\title{
Indução da calogênese em segmentos foliares de seringueira (Hevea spp.) na
}

\section{Amazônia Sul-Ocidental}

\author{
Induction of calogenesis in leaf segment of rubber (hevea spp.) in the South-Western Amazon \\ Inducción de la calogénesis en segmentos de hojas de árboles de caucho (Hevea spp.) en la \\ Amazônia Sudoccidental
}

Recebido: 28/06/2021 | Revisado: 05/07/2021 | Aceito: 13/07/2021 | Publicado: 23/07/2021

Ana Claudia Lopes da Silva
ORCID: https://orcid.org/0000-0002-7954-8989
Universidade Federal do Acre, Brasil
E-mail: acl.engenhariaflorestal@ hotmail.com
Cândida Elisa Manfio
ORCID: https://orcid.org/0000-0003-4089-6502
E-mail: candidamanfio@gmail.com
João Ricardo Avelino Leão
Empresa de Pesquisa Agropecuária e Extensão Rul de
ORCID: https://orcid.org/0000-0002-0669-4715
E-mail: joao.aleao@ifac.edu.br
Josiane Celerino de Carvalho
Instituto Federal de Educação, Ciência e Tecnologia do Acre, Brasil
ORCID: https://orcid.org/0000-0001-7986-4693
Enstituto Nacional de Pesquisas da Amazônia, Brasil
E-mail:josiane.celerino@gmail.com
José Francisco de Carvalho Gonçalves
ORCID: https://orcid.org/0000-0001-9197-4617
Instituto Nacional de Pesquisas da Amazônia, Brasil
E-mail: jfc@inpa.gov.br
Andrea Raposo
ORCID: https://orcid.org/0000-0001-9640-4218
Empresa Brasileira de Pesquisa Agropecuária, Brasil
E-mail: andrea.raposo@embrapa.br

\begin{abstract}
Resumo
Mesmo considerando os avanços nos estudos de micropropagação em Hevea spp., a compreensão dos estímulos e condições necessárias para o estabelecimento do cultivo in vitro ainda são limitadas. Uma das razões para isto acontecer é devido à falta de um protocolo eficiente para a propagação de clones elites de seringueira em larga escala. Neste sentido, investigamos o efeito do ácido 2,4-diclorofenoxiacético na indução de calos em segmentos foliares de Hevea spp., bem como o uso do PPM $^{\circledR}$ (Plant Preservative Mixture) na inibição de contaminações. Folhas juvenis de seringueira foram inoculadas em meio de cultura MS (Murashig Skoog) suplementado com 2,4-D $(0 ; 0,25 ; 0,5 ; 1,0$; 2,0 e 4,0 $\left.\mathrm{mg} \mathrm{L}^{-1}\right)$ com biocida PPM $^{\circledR}\left(0\right.$ e 1,0 $\left.\mathrm{mL} \mathrm{L}^{-1}\right)$. Após 60 dias foi possível observar maior porcentagem de sobrevivência e expressiva oxidação fenólica na presença do $\mathrm{PPM}^{\circledR}$. As concentrações de 2,4-D (2,0 e 4,0 mg L $\left.\mathrm{m}^{-1}\right)$ combinadas com PPM ${ }^{\circledR}\left(1 \mathrm{~mL} \mathrm{~L}^{-1}\right)$ foram eficientes na inibição de contaminações microbianas. A indução de calo ocorreu no tratamento contendo $1 \mathrm{mg} \mathrm{L}^{-1}$ de 2,4-D e $1 \mathrm{~mL} \mathrm{~L}^{-1}$ de $\mathrm{PPM}^{\circledR} \mathrm{e}$ formou um calo compacto com coloração branca. O protocolo utilizado neste trabalho foi eficiente para desinfestação dos explantes foliares de Hevea spp.
\end{abstract}

Palavras-chave: Cultura de tecidos; Calos; $\mathrm{PPM}^{\circledR}$; Regulador vegetal.

\begin{abstract}
Even considering the advances in the micropropagation studies in Hevea spp., the understanding of the stimuli and conditions necessary for the establishment of in vitro culture are still limited. One of the reasons this happens is due to the lack of an efficient protocol for the propagation of large-scale elite clones of rubber tree. In this sense, we investigated the effect of 2,4-dichlorophenoxyacetic acid on the induction of corns in leaf segments of Hevea spp., As well as the use of PPM ${ }^{\circledR}$ (Plant Preservative Mixture) in the inhibition of microbial contamination. Young rubber tree leaves were inoculated in MS (Murashig Skoog) culture medium supplemented with 2,4-D $(0 ; 0.25 ; 0.5 ; 1.0 ; 2.0$ and $4.0 \mathrm{mg} \mathrm{L}-1)$ with PPM® biocide $\left(0\right.$ and $\left.1.0-\mathrm{mL} \mathrm{L}^{-1}\right)$. After 60 days it was possible to observe the highest percentage of areas and an expressive phenolic oxidation in the presence of PPM $®$. The 2,4-D $\left(2.0\right.$ and $\left.4.0 \mathrm{mg} \mathrm{L}^{-1}\right)$ restrictions combined with PPM ${ }^{\circledR}\left(1 \mathrm{~mL} \mathrm{~L}^{-1}\right)$ were effective in inhibiting microbial contamination. Callus induction occurred in the treatment containing $1 \mathrm{mg} \mathrm{L}^{-1}$ of 2,4-D and $1 \mathrm{~mL} \mathrm{~L}^{-1}$ of PPM® and formed a compact callus with white coloring. The protocol used in this work was efficient for disinfesting leaf explants of Hevea spp.
\end{abstract}


Keywords: Tissue culture; Callus; $\mathrm{PPM}^{\circledR}$; Vegetal regulator.

\section{Resumen}

Incluso considerando los avances en los estudios de micropropagación en Hevea spp., el conocimiento de los estímulos y las condiciones necesarias para el establecimiento del cultivo in vitro todavía son limitado, ya que no existe un protocolo eficiente para la propagación de clones élite a gran escala del seringueira. En este sentido, investigamos el efecto del ácido 2,4-diclorofenoxiacético sobre la inducción de callos en segmentos foliares de Hevea spp., así como el uso del PPM $^{\circledR}$ (Plant Preservative Mixture) en la inhibición de la contaminación microbiana. Se inocularon hojas jóvenes de árboles de caucho en medio de cultivo MS (Murashig Skoog) suplementado con 2,4-D (0; 0,$25 ; 0,5 ; 1,0 ; 2,0$ e $\left.4,0 \mathrm{mg} \mathrm{L}^{-1}\right)$ y biocida $\mathrm{PPM}^{\circledast}\left(0\right.$ e $\left.1,0 \mathrm{~mL} \mathrm{~L}^{-1}\right)$. A los 60 días se pudo observar un mayor porcentaje de supervivencia y una expresiva oxidación fenólica en la presencia del PPM $^{\circledR}$. Las concetraciones del 2,4-D (2.0 y $\left.4.0 \mathrm{mg} \mathrm{L}^{-1}\right)$ combinadas con PPM ${ }^{\circledR}\left(1 \mathrm{~mL} \mathrm{~L}^{-1}\right)$ fueron eficientes para inhibir la contaminación microbiana. La inducción de callos ocurrió en el tratamiento que contenía $1 \mathrm{mg} \mathrm{L}^{-1}$ de 2,4-D y $1 \mathrm{~mL} \mathrm{~L}^{-1}$ de PPM ${ }^{\circledR}$ y formó un callo compacto con coloración blanca. El protocolo utilizado en este trabajo fue eficaz para desinfectar explantes de hojas de Hevea spp.

Palabras clave: Cultura de tejidos; Callos; $\mathrm{PPM}^{\circledR}$; Regulador de planta.

\section{Introdução}

A seringueira (Hevea brasiliensis) é uma espécie nativa da Amazônia pertencente ao gênero Hevea e à família Euphorbiaceae, tem como área de ocorrência e dispersão natural, a Amazônia brasileira e países próximos, como a Bolívia, Colômbia, Peru, Venezuela, Equador, Suriname e Guiana (Secco, 2008; Priyadarshan, 2017). As espécies pertencentes ao gênero Hevea tem potencial econômico devido apresentar fontes de produção de borracha natural e, a $H$. brasiliensis é a espécie mais importante economicamente (Moradpour, Aziz, \& Abdullah, 2016; Krickl, Didier, \& Werner, 2017; Smith, Lu, To, Mienmany, \& Soukphaxay, 2020; Perron et al., 2021).

No que se refere a borracha natural proveniente da $\mathrm{H}$. brasiliensis, é possível afirmar que as suas propriedades biopolímeras são únicas e não podem ser replicadas por alternativas sintéticas, o que a torna matéria-prima insubstituível para muitas aplicações. Quando comparada com a borracha sintética, a borracha natural apresenta benefícios como proporcionar uma baixa geração de calor sob atrito, alta resistência a rupturas, boa resistência a abrasão, além das suas características elásticas e natureza à prova d'água, que são consideradas excelentes para aplicação em composições de pneus, material bélico, transporte e outros (Zwart, Krabbenborg, \& Zwier, 2015; Men, Wang, Chen, Zhang, \& Xian, 2019). Devido à crescente demanda por borracha natural, a cultura de tecidos e a genética são técnicas promissoras que podem ser usadas na seleção precoce para o melhoramento em Hevea e produção em larga escala (Venkatachalam, Geetha, Sangeetha, \& Thulaseedharan, 2013).

Espécies lenhosas vêm sendo propagadas com relativo sucesso por meio da cultura de tecidos (Gomes, Paiva, Herrera, \& Paiva, 2010). Essa técnica permite a rápida multiplicação de cultivares com características desejáveis, geneticamente idênticas e livres de doenças, sendo realizada por via direta (gemas adventícias desenvolvidas diretamente sobre o explante) ou indireta (proliferação e crescimento de calos por indução dos explantes) (Prammanee, Thumjamras, Chiemsombat, \& Pipattanawong, 2011). No entanto, as contaminações causadas por microrganismos é um fator limitante na micropropagação de espécies lenhosas (Palú, Corrêa, Suzuki, \& Boliani, 2011), e na micropropagação da espécie H. brasiliensis, estabelecer uma cultura asséptica e sem ocorrência de oxidações tem sido um desafio (Moradpour et al., 2016).

O uso do Plant Preservative Mixture ${ }^{\circledR}$ (PPM) é uma das alternativas para prevenir e controlar contaminações microbianas em meio de cultivo in vitro, atuando como eletrófilos na reação de cisteína e glutationa (Niedz, 1998), uma vez que é um biocida sintético que penetra na parede celular e membranas de micro-organismos e inibe diversas enzimas mitocondriais, o PPM ${ }^{\circledast}$ atuando como um biocida de amplo espectro (Compton \& Koch, 2001).

O sucesso do cultivo in vitro está diretamente relacionado com a manipulação isolada ou combinada de reguladores vegetais como auxinas e citocininas (Wang et al., 2016). Segundo Tarrahi e Rezanejad (2013), esses reguladores, ácido 2,4- 
diclorofenoxiacético (2,4-D) é uma importante auxina sintética normalmente usada no meio de cultura como agente de indução de calos. Para o desenvolvimento de protocolos de micropropagação de uma dada espécie, é necessário primeiro estabelecê-la in vitro. No entanto, as exigências requeridas em condições in vitro variam muito entre as espécies (Miranda, Titon, Pereira, Fernandes, \& Santos, 2019).

No que diz respeito a organogênese in vitro em espécies de Hevea, ainda não existe um protocolo que seja eficiente para a propagação de clones produtivos em larga escala. Estudos têm sido realizados com micropropagação e fatores relacionados a produção de látex utilizando a cultura de tecidos vegetais com uma estratégia. Alguns avanços foram obtidos recentemente na micropropagação de $H$. brasiliensis, onde se obteve plântulas in vitro com sistemas radicular e aéreo desenvolvidos, porém estas plântulas estagnaram e morreram ainda no meio de cultura (Ighere, Anthony; Olayode, \& Sunday, 2011; Antwi-Wiredu, Amiteye, Diawuoh, Asumeng, \& Klu, 2018). As principais limitações a serem resolvidas para esta espécie são hiperidricidade, oxidação e contaminação endógena (Máximo, Santos, Martins, Mendonça, \& Paiva, 2018).

Devido ao grande potencial econômico da borracha natural proveniente da seringueira, pesquisas com esta espécie estão voltadas principalmente para a produção de látex, visando propagação de clones de maior produtividade e produção precoce. Mesmo sendo possível identificar avanços nos estudos de micropropagação em Hevea spp., essa espécie ainda é propagada tradicionalmente por enxertia de mudas não selecionadas e a compreensão dos estímulos e condições necessárias para o estabelecimento do cultivo in vitro deste gênero permanece a necessidade de ser esclarecida, uma vez que ainda não há um protocolo que seja eficiente para a propagação de clones elites em larga escala. Aqui, nós hipotetizamos que o equilíbrio do meio de cultivo com substâncias controle e/ou minimize contaminações microbianas pode resultar em benefício para o ajustamento de protocolo para a propagação da seringueira. Neste contexto, o presente estudo teve como objetivo investigar o efeito do regulador vegetal ácido 2,4-diclorofenoxiacético na indução de calos em segmentos foliares de seringueira (Hevea spp.), bem como o uso do $\mathrm{PPM}^{\circledR}$ na inibição de contaminações microbianas.

\section{Metodologia}

O experimento foi realizado no Laboratório de Morfogênese e Biologia Molecular da Embrapa Acre. Primeiramente, os explantes de folhas juvenis de seringueira foram coletados de árvores matrizes do clone FDR 5865 do banco de germoplasma do Campo Experimental da Embrapa Acre. A área experimental para a coleta do material vegetativo está localizada na região Sudeste do Estado do Acre (10U01'28"S,67U42'19"W), de clima equatorial (Am de Köppen), quente e úmido, com estação caracterizada por período de três meses de seca (junho a agosto) e auge do regime pluviométrico em fevereiro, apresentando temperatura média anual de $24,5{ }^{\circ} \mathrm{C}$, no município de Rio Branco-AC (Duarte, 2006).

Os segmentos foliares coletados (72 amostras) foram conduzidos ao laboratório e cortados no sentido longitudinal em forma geométrica com aproximadamente $1 \times 1 \mathrm{~cm}$, para visualização e contabilização dos calos ao final do estudo (Figura 1). Inicialmente foi realizado pré-assepsia nos explantes (lavagem em água corrente com detergente neutro durante 10 minutos, seguidos de lavagem em água destilada e autoclavada três vezes). 
Figura 1. Explante de folha de seringueira (Hevea spp.) indicando as regiões utilizadas como fonte de explante no cultivo in vitro.

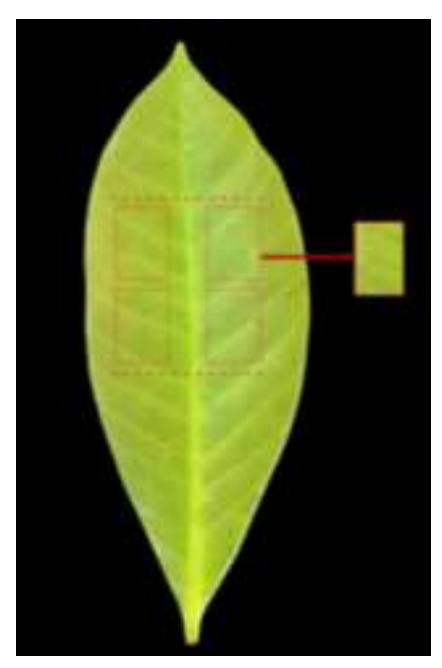

Fonte: Autores.

Após a realização da assepsia dentro da câmara de fluxo laminar, os explantes foram submetidos a uma solução de álcool 70\% (v/v) por $1 \mathrm{~min}$., seguido de hipoclorito de sódio 2,5\% com cinco gotas de detergente comercial neutro durante 20 min. Em seguida, passaram por um tríplice lavagem em água destilada estéril e logo após foram imersos em solução de PVP (polivinilpirrolidona) $\left(1 \mathrm{~g} \mathrm{~L}^{-1}\right)$ para evitar a oxidação fenólica dos explantes.

Os explantes foram inoculados em tubos de ensaio contendo $30 \mathrm{~mL}$ de meio de cultura MS (Murashige \& Skoog, 1962), suplementado com $30 \mathrm{~g} \mathrm{~L}^{-1}$ de sacarose e com diferentes concentrações do regulador vegetal 2,4-D (ácido 2,4diclorofenoxiacético) $\left(0,0 ; 0,25 ; 0,5 ; 1,0 ; 2,0 ; 4,0 \mathrm{mg} \mathrm{L}^{-1}\right)$ combinados com $\operatorname{PPM}^{\circledR}\left(0,0 ; 1,0 \mathrm{~mL} \mathrm{~L}^{-1}\right)$. O pH foi ajustado em 5,8 antes da adição de ágar $\left(6 \mathrm{~g} \mathrm{~L}^{-1}\right)$, posteriormente foram autoclavados a $120{ }^{\circ} \mathrm{C}$ e $1 \mathrm{~atm}$, durante $20 \mathrm{~min}$. Em seguida, os tubos foram acondicionados na sala de crescimento a $25 \pm 2{ }^{\circ} \mathrm{C}$, onde permaneceram na ausência luminosa durante 30 dias. Após este tempo, os explantes ficaram expostos a irradiância de $22,8 \mu \mathrm{mol} / \mathrm{m}^{2} / \mathrm{s}$ de fluxos de fótons fotossintéticos e $16 \mathrm{~h}$ de fotoperíodo durante 30 dias. As avaliações foram realizadas após 30 e 60 dias de cultivo, onde foram avaliados sobrevivência, oxidação fenólica, contaminação microbiana e formação de calos.

O delineamento inteiramente casualizado (DIC) foi em esquema fatorial, diferentes concentrações de 2,4-D e de PPM $^{\circledR}$, totalizando 12 tratamentos com 6 repetições, sendo que cada repetição foi composta de 4 explantes.

As análises estatísticas foram submetidas ao teste de normalidade, teste Kolmogorov-Smirnov e a homogeneidade das variâncias, teste de Bartlett, as variáveis foram transformadas, sempre que necessário, pela função: raiz de $\mathrm{x}+0,5$, sendo $\mathrm{x} o$ valor observado. Os dados foram submetidos a análise de variância e comparados pelo teste de Tukey (5\%). O programa estatístico utilizado foi Sisvar 5.1 (Sistema para Análise de Variância) para as análises estatísticas (Ferreira, 2014) e para a montagem dos gráficos foi o programa SigmaPlot 2.0.

\section{Resultados}

As primeiras avaliações foram feitas aos 30 dias na ausência de luz, observamos que todos os tratamentos apresentaram oxidação nas bordas dos segmentos foliares (Figura 2). No entanto, aos 60 dias, verificou-se altas taxas de sobrevivência dos explantes, cerca de 93\% (Tabela 1, Figura 3A), apresentando efeito significativo $(p<0,05)$ para as diferentes concentrações de $\operatorname{PPM}^{\circledR}$ (Tabela 1). 
Figura 2. Oxidação fenólica em segmentos de folhas juvenis de seringueira (Hevea spp.) em resposta aos tratamentos de indução de calogênese.

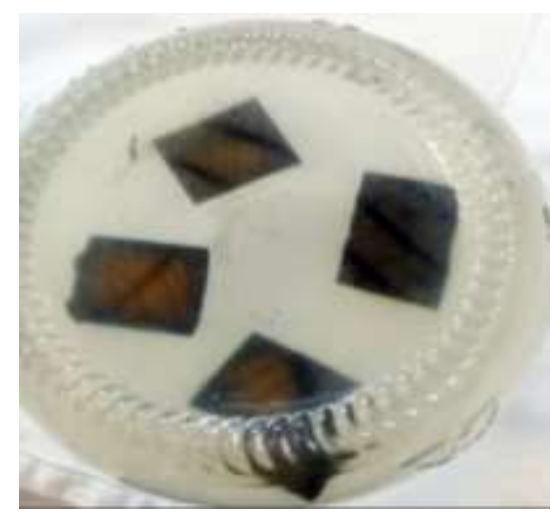

Fonte: Autores.

Tabela 1. Porcentagem sobrevivência de explantes foliares de seringueira (Hevea spp.) em resposta aos tratamentos para indução de calogênese.

\begin{tabular}{rc}
\hline \multirow{2}{*}{ Tratamento } & Sobrevivência \\
\cline { 2 - 2 } & Média \\
\hline $2,4-\mathrm{D}^{*}$ & $72,91^{\mathrm{b}}$ \\
$2,4-\mathrm{D}+\mathrm{PPM}^{* *}$ & $93,05^{\mathrm{a}}$ \\
\hline CV $(\%)$ & 16,44 \\
\hline
\end{tabular}

Médias seguidas de mesma letra na coluna, não diferem entre si pelo teste de Tukey, ao nível de 5\% de probabilidade. * Auxina: 2,4-D - Ácido 2,4 diclorofenoxiacético **Biocida: PPM $^{\circledR}$-Plant Preservative Mixture.

Fonte: Autores. 
Figura 3. Porcentagem de (A) sobrevivência, (B) oxidação fenólica e (C) contaminação em segmentos foliares de seringueira (Hevea spp.) em resposta aos tratamentos de indução de calogênese.
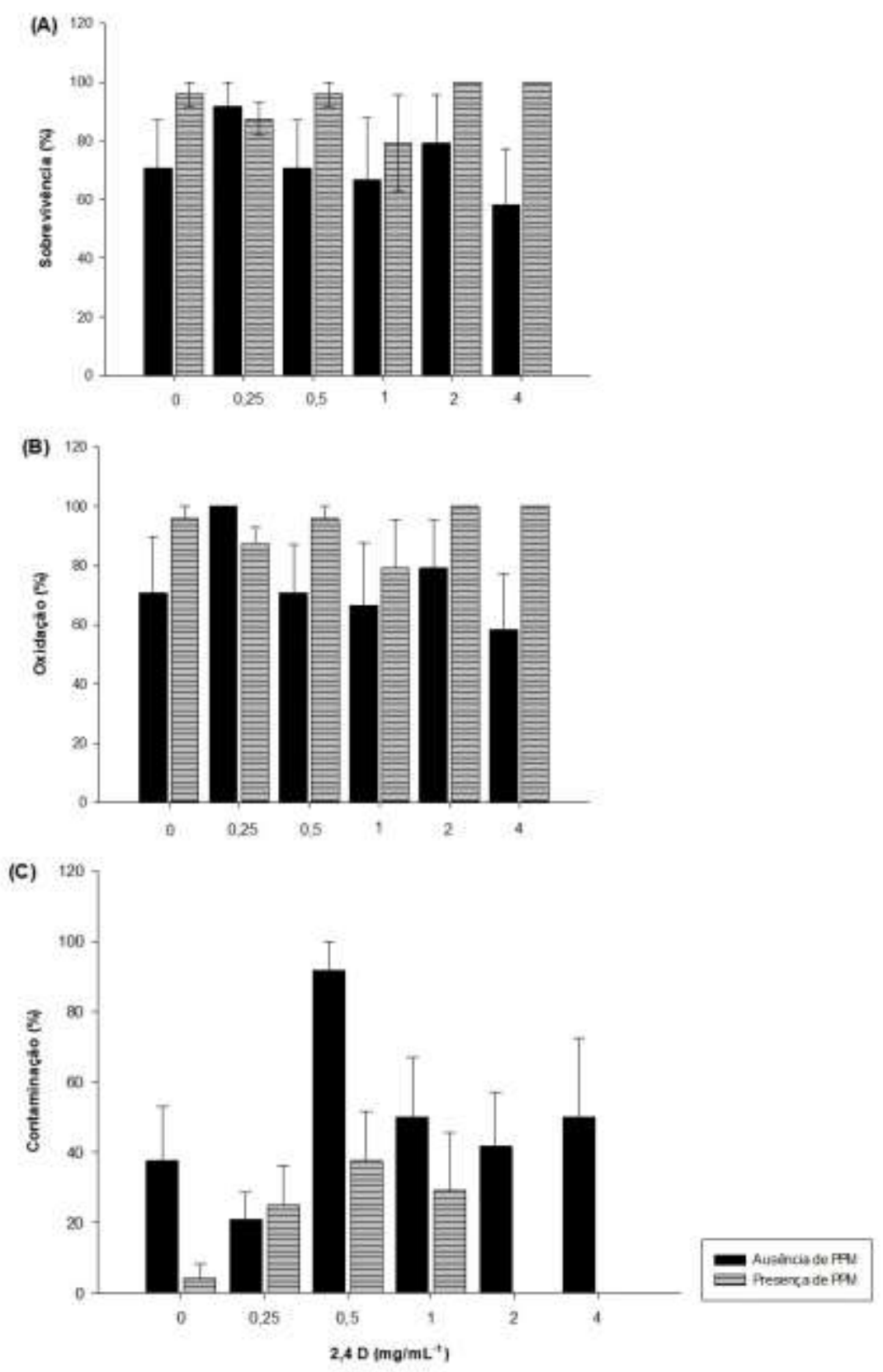

Fonte: Autores.

Já as diferentes concentrações do regulador vegetal 2,4-D, não observamos efeito significativo ( $p>0,05)$ assim como na interação entre estes dois fatores. As oxidações fenólicas apresentaram diferenças significativas apenas para o uso do PPM ${ }^{\circledR}$, onde a média de oxidação em todos os tratamentos foi cerca de 93\%. Quanto as concentrações de 2,4-D não tiveram efeito significativo assim como a interação entre estes dois fatores (Tabela 2). Mesmo não havendo diferença estatística conforme pode ser observado na Figura 3B, verificou-se que o uso do PPM ${ }^{\circledR}$ proporcionou uma maior porcentagem de oxidação fenólica nos segmentos foliares. 
Tabela 2. Resumo da ANOVA para as variáveis taxa de sobrevivência, oxidação fenólica e taxa de contaminação em função das doses de 2,4D e da presença de PPM. Dados transformados: Raiz quadrada de Y + 0.5 - SQRT ( Y + 0.5 ).

\begin{tabular}{cllll}
\hline F.V. & G.L. & \multicolumn{3}{c}{ Quadrado médio } \\
\cline { 3 - 5 } & & Sobrevivência & Oxidação & Contaminação \\
\hline $2,4 \mathrm{D}$ & 5 & $0,0433^{\text {ns }}$ & $0,0536^{\text {ns }}$ & $0,0794^{\text {ns }}$ \\
\hline PPM & 2 & $0,7824^{*}$ & $0,7925^{*}$ & $1,9799^{*}$ \\
\hline $2,4 \mathrm{D} \times$ PPM & 5 & $0,0522^{\text {ns }}$ & $0,0624^{\text {ns }}$ & $0,1077^{\text {ns }}$ \\
\hline CV\% & 16,44 & 17,53 & 26,63 \\
\hline
\end{tabular}

* Teste F significativo ao nível de 5\% de probabilidade, ns não significativo. Fonte: Autores.

Avaliando as contaminações por microorganismos, a interação dos fatores concentrações de 2,4-D e presença $1 \mathrm{~mL} \mathrm{~L}^{-1}$ de PPM ${ }^{\circledR}$ aliado ao procedimento de desinfestação empregado durante a fase de manipulação dos explantes, observamos que contribuiu para a redução da contaminação microbiana, mostrando a eficácia desse protocolo no que diz respeito as contaminações, como observou-se para contaminações bacterianas, sem contaminação (0\%) em todos os tratamentos. Apesar de apresentar baixo índice de contaminação fúngica onde a média entre todos os tratamentos testados foi de $23 \%$ (dados não apresentados). A presença $1 \mathrm{~mL} \mathrm{~L}^{-1}$ de $\mathrm{PPM}^{\circledR}$ aliado as concentrações de 2 e $4 \mathrm{mg} \mathrm{L}^{-1}$ de 2,4-D no meio de cultura apresentou efeito significativo no controle de contaminação fúngica (0\%), conforme pode ser observado na figura 3C. A baixa porcentagem de contaminação obtida reflete a eficiência do método de desinfestação adotado neste trabalho.

Em relação a formação de calos, não foi observada diferença significativa entre os tratamentos empregados ( $p>0,05)$, pois apresentou baixo índice de indução de calos, sendo possível observação em um explante no tratamento contendo $1 \mathrm{mg} \mathrm{L}^{-1}$ de 2,4-D e $1 \mathrm{~mL} \mathrm{~L}^{-1}$ de PPM $^{\circledR}$, iniciando sua formação após 30 dias de cultivo, com 60 dias ele apresentou consistência compacta e coloração branca (Figura 4).

Figura 4. Segmentos foliares de seringueira (Hevea spp.) após 60 dias de incubação em meio de cultura MS suplementado com $1 \mathrm{mg} \mathrm{L}^{-1}$ de 2,4-D e $1 \mathrm{~mL} \mathrm{~L}^{-1}$ de PPM, com a presença de calo.

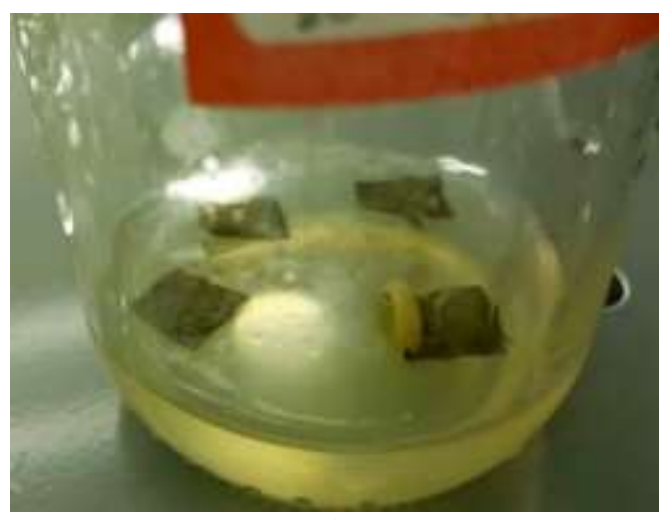

Fonte: Autores.

Passados os 60 dias de cultivo, o calo foi transferido para novo meio de cultivo MS com a mesma formulação de origem, a fim de promover continuidade em seu desenvolvimento. Porém, este oxidou e morreu após 90 dias de cultivo (Figura $5)$. 
Figura 5. Segmento foliar de seringueira (Hevea spp.) com a presença de calo oxidado após 90 dias de incubação em meio de cultura MS.

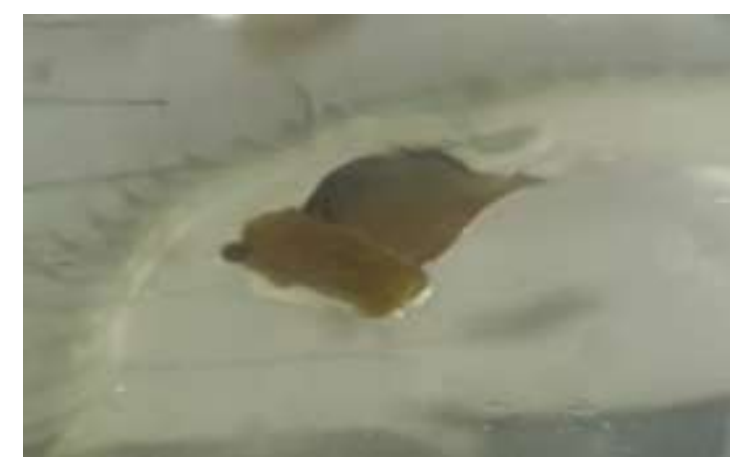

Fonte: Autores.

\section{Discussão}

A oxidação nas bordas dos explantes foliares (Figura 4) foi observada nas primeiras avaliações, aos 30 dias mesmo na ausência de luz, mostrando as dificuldades encontradas em estabelecer protocolos para espécies de Hevea spp., uma vez que, o cultivo direto do material após a desinfestação e a não ambientação no escuro promovem alto índice de oxidação fenólica, inviabilizando o cultivo (Freitas, Contim, Dias, Ferreira, \& Santos, 2011). No entanto, apesar da oxidação fenólica ser um problema nos cultivos in vitro, também podem ser um indicativo para o início do processo de desenvolvimento do explante. Adicionalmente, esse estresse oxidativo é necessário para a indução no processo de desenvolvimento do explante. O excesso de compostos fenólicos desencadeia a oxidação, levando ao escurecimento do calo, à senescência dos tecidos e até mesmo a moralidade do mesmo (Jo, Dos Santos, Bueno, Barbosa, \& Floh, 2014; Wickramasuriya \& Dunwell, 2015). No entanto, a variação de intensidade desse processo de oxidação pode ser inerente às diferentes espécies ou variedades (Paiva, Paiva \& Pasqual, 2007).

Aos 60 dias de cultivo, verificou-se alta porcentagem de sobrevivência dos explantes e eficiência no controle de contaminação bacteriana. Estudos realizados com gemas axilares de erva-mate (Ilex paraguariensis), com o objetivo de estabelecer um protocolo de desinfestação utilizaram as mesmas concentrações de PPM $^{\circledR}$ descritas no presente trabalho e corroborando com o presente estudo, encontraram altas taxas de sobrevivência cerca de $98 \%$, sendo eficaz para o controle da contaminação (Dutra, Hansel, \& Wendling, 2008). Por outro lado, proporcionou altas taxas de oxidação (100\%), apresentando efeito fitotóxico para a cultura. Estudos de Leão, Raposo, Da Silva e Sampaio (2020), observaram o estabelecimento de bambu usando 2,0 $\mathrm{mL} \mathrm{L}^{-1}$ de $\mathrm{PPM}^{\circledast}$, o que mostrou ser eficiente contra o ataque de bactérias e fungos, e ainda benéfico para a regeneração e sobrevivência de rebentos.

A oxidação fenólica é um dos problemas mais frequentes, especialmente no período de estabelecimento do cultivo in vitro de espécies lenhosas (Sato et al., 2001). A exsudação de compostos fenólicos causa escurecimento e necrose dos tecidos que sofreram algum tipo de injúria, após a lesão surge formação de quinonas (substância fitotóxica) em função da ação de enzimas polifenases com os compostos fenólicos, obstando a assimilação dos componentes do meio de cultura e o desenvolvimento da planta (Azofeifa, 2009; Mudoi, Saikia, \& Borthakur, 2014).

Contaminações são consideradas como um dos fatores limitantes à cultura de tecidos de espécies lenhosas, merecendo atenção especial. Vale ressaltar, que muitos contaminantes são observados somente após algumas semanas de cultivo, o que indica a possibilidade de microrganismos endofíticos existentes nos tecidos (Palu, 2011). Afim de contornar essa barreira, estudos tem apontado o uso satisfatório do $\mathrm{PPM}^{\circledR}$ na eliminação dos contaminantes em várias espécies na cultura de tecidos vegetais (Dutra et al., 2008; Leão et al., 2020). 
Compton e Koch (2001), ao investigar os efeitos de diferentes concentrações de PPM ${ }^{\circledR}$ na organogênese in vitro de melão (Cucumis melo L.), petúnia (Petunia Juss) e tabaco (Nicotiniana L.), constataram que resposta morfogenética referente ao uso de diferentes concentrações do biocida depende de cada espécie, podendo ou não afetar a regeneração in vitro. No presente estudo foi utilizado uma dosagem constante deste biocida $\left(1 \mathrm{~mL} \mathrm{~L}^{-1}\right)$, tornando-se necessário outras pesquisas com dosagens mais baixas para verificar o efeito desta substância sobre o estabelecimento de condições in vitro, em explantes foliares de Hevea spp.

\section{Conclusão}

O protocolo utilizado $1 \mathrm{~mL} \mathrm{~L}^{-1}$ de $\mathrm{PPM}^{\circledR}$ foi capaz de promover uma eficiente desinfestação dos explantes foliares de Hevea spp.. No entanto, as concentrações utilizadas de 2.4 D não foram responsivas ao ponto de consolidar indução robusta de calogênese. $\mathrm{O}$ fato é que na concentração de $1 \mathrm{mg} \mathrm{L}^{-1}$ de 2,4-D observou se presença de calogênese e esta evidência sugere que o aprofundamento na abordagem dos níveis de concentração do 2,4-D e testagem de tecidos mais jovens com uma prevenção efetiva de oxidações pode ser a melhor alternativa para se obter respostas seguras para indução de calogênese a partir de folhas de seringueira.

\section{Agradecimentos}

Os autores agradecem a Empresa Brasileira de Pesquisa Agropecuária, Embrapa Acre pelo suporte e apoio financeiro, tornando possível a execução desta pesquisa.

\section{Referências}

Antwi-Wiredu, A., Amiteye, S., Diawuoh, R. A., Asumeng, A. K., \& Klu, G. Y. P. (2018). Propagation of Rubber Tree (Hevea brasiliensis) Using Shoot-Tip and Nodal Cutting Explants. International Journal of Advances in Scientific Research and Engineering. 6, 38-50. http://dx.doi.org/10.7324/IJASRE.2018.32743.

Azofeifa, A. (2009). Problemas de oxidación y oscurecimiento de explantes cultivados in vitro. Agronomía Mesoamericana. 20, 153-175. http://dx.doi.org/10.15517/AM.V20I1.4990.

Compton, M. E., \& Koch, J. M. (2001). Influence of Plant Preservative Mixture (PPM) on adventitious organogenesis in melon, petunia and tobacco. In Vitro Cell Development Biology-Plant, 37, 259-261. https://doi.org/10.1007 / s11627-001-0046-6.

Duarte, A. F. (2006). Aspectos da Climatologia do Acre, Brasil, com base no intervalo 1971-2000. Revista Brasileira de Meteorologia, 21 (3b), 308 - 317.

Dutra. (2008). Introdução ao cultivo in vitro de Erva-mate (Ilex paraguariensis). Colombo: Embrapa Florestas, 38. http://www.infoteca.cnptia.embrapa.br/infoteca/handle/doc/315215

Ferreira, D. F. (2014). Sisvar: a Guide for its Bootstrap procedures in multiple comparisons. Ciência e Agrotecnologia, 38 (2), $109-112$.

Freitas, D. V., Contim, L. A. S., Dias, D. P., Ferreira, W. C., \& Santos, R. C. (2011). Estabelecimento in vitro de Pau-rosa (Aniba rosaeodora Ducke): efeito do benomyl como regulador de crescimento. Enciclopédia Biosfera, 7(13), 489-496. https://conhecer.org.br/ojs/index.php/biosfera/article/view/4138.

Gomes, G. A. C., Paiva, R., Herrera, R. C., \& Paiva, P. D. O. (2010). Micropropagation of Maclura tinctoria L.: an endangered woody species. Revista Árvore, 34 (1), 25-30. https://doi.org/10.1590/S0100-67622010000100003.

Ighere, D. A., Anthony, O. J. E., Olayode, M. F. O., Sunday, A. (2011). In vitro culture of Hevea brasiliensis (rubber tree) embryo. Journal of Plant Breeding and Crop Science, 9,185-189.

Jo, L., Dos Santos, A. L. W., Bueno, C. A., Barbosa, H. R., \& Floh, E. I. S. (2014). Proteomic analysis and polyamines, ethylene and reactive oxygen species levels of Araucaria angustifolia (Brazilian pine) embryogenic cultures with different embryogenic potential. Tree Physiology, 34, 94-104. https://doi.org/10.1093/treephys/tpt102

Krickl, S., Didier, T., \& Werner, K. (2017). Investigation of ethanolamine stabilized natural rubber latex from Taraxacum kok-saghyz and from Hevea brasiliensis using zeta-potential and dynamic light scattering measurements. Industrial Crops and Products, 103, 169-174. https://doi.org/10.1016/j.indcrop.2017.03.046.

Leão, J. R. A., Raposo, A., Da Silva, A. C. L., Sampaio P. T. B. (2020). Control of contaminants in the in vitro establishment of Guadua latifolia. Pesquisa Agropecuária Tropical, 50, 1-7. https://doi.org/10.1590/1983-40632020v5063541. 
Máximo, W. P. F., Santos, P. A. A., Martins, G. S., Mendonça, E. G., \& Paiva, L. V. (2018). In vitro multiplication of eucalyptus hybrid via temporary immersion bioreactor: culture media and cytokinin effects. Crop Breeding and Applied Biotechnology. 18, 131-138. https://doi.org/10.1590/1984$70332018 \mathrm{v} 18 \mathrm{n} 2 \mathrm{a} 19$

Men, X., Wang, F., Chen, G. Q., Zhang, H. B., \& Xian, M. (2019). Biosynthesis of Natural Rubber: Current State and Perspectives. International Journal of Molecular Sciences, 20(1), 50. https://doi.org/10.1590/1984-70332018v18n2a19.

Miranda, N. A., Titon, M., Pereira, I. M., Fernandes, J. S. C., \& Santos, M. M. (2019). Estabelecimento in vitro de Eremanthus incanus. Pesquisa Florestal Brasileira, 39 (1),1-7. https://doi.org/10.4336/2019.pfb.39e201701525.

Moradpour, M., Aziz, M. A., \& Abdullah, S. N. A. E. (2016). Stablishment of in vitro Culture of Rubber (Hevea brasiliensis) from Field-derived Explants: Effective Role of Silver Nanoparticles in Reducing Contamination and Browning. Journal of Nanomedicine \& Nanotechnology. 7(3), 1-7. https://doi.org/10.4172/2157-7439.1000375.

Mudoi, K. D., Saikia, S. P., \& Borthakur, M. (2014). Effect of nodal positions, seasonal variations, shoot clump and growth regulators on micropropagation of commercially important bamboo, Bambusa nutans Wall. ex. Munro. African Journal of Biotechnology. 13(19), 1961-1972. https://10.5897/ AJB2014.13659

Murashige, T., \& Skoog, F. (1962). A revised medium for rapid growth and biossays with tissue cultures. Physiologia Plantarum, 15, 473-497. https://doi.org/10.1111/j.1399-3054.1962.tb08052.x.

Niedz, R. P. (1998). Using isothiazolone biocides to control microbial and fungal contaminants in plant tissue cultures. Horttechnology, 8, (4), 598-601. https://doi.org/10.21273/HORTTECH.8.4.598.

Paiva, P. D. O., Paiva, R., \& Pasqual, M. (2007). Controle de oxidação no cultivo in vitro de embriões de estrelícia (Strelitzia reginae). Revista Brasileira de Horticultura Ornamental, 13(2), 107-112. https://doi.org/10.14295/rbho.v13i2.213.

Palú, E. G., Corrêa, L. S., Suzuki, A. N., \& Boliani, A. C. (2011). Uso de antibióticos para o controle de bactérias endógenas visando à micropropagação da figueira. Revista Brasileira de Fruticultura, 33, 587-592. https://doi.org/10.1590/S0100-29452011000200031.

Perron, T., Mareschal, L., Laclau, J. P., Deffontaines, L., Deleporte, P., Masson, A., Cauchy, T., \& Gay, F. (2021) Dynamics of biomass and nutrient accumulation in rubber (Hevea brasiliensis) plantations established on two soil types: Implications for nutrient management over the immature phase. Industrial Crops and Products 159: 113084. https://doi.org/10.1016/j.indcrop.2020.113084.

Prammanee, S., Thumjamras, S., Chiemsombat, P., \& Pipattanawong, N. (2011). Efficient shoot regeneration from direct apical meristem tissue to produce virus-free purple passion fruit plants. Crop Protection, 30, 1425-1429. https://doi.org/10.1016/j.cropro.2011.07.008.

Priyadarshan, P. M. (2017). Biology of Hevea Rubber. Springer.

Sato, A. Y., Dias, H. C. T.,AAndrade, L. A., \& Souza, V. C (2001). Micropropagação de Celtis sp.: controle da contaminação e oxidação. Cerne, 7 (2),117-123. https://www.redalyc.org/articulo.oa?id=74470211

Secco, R. S. (2008). A botânica da seringueira. In: Alvarenga, A. P., Carmo, C.A. F. S. (Coord.) Seringueira. (pp. 3-23) Epamig .

Smith, H., Lu, J., To, P. X., Mienmany, S., \& Soukphaxay, K. (2020). Rubber Plantation Value Chains in Laos: Opportunities and Constraints in Policy, Legality and Wood Processing, report produced for ACIAR project FST/2016/151 - Advancing enhanced wood manufacturing industries in Laos and Australia and Forest Trends. https://www.forest-trends.org/wp-content/uploads/2020/07/Rubber-Plantation-Value-Chains-in-Laos.pdf.

Tarrahi, R., \& Rezanejad, F. (2013). Callogenesis and production of anthocyanin and chlorophyll in callus cultures of vegetative and floral explants in Rosa gallica and Rosa hybrid (Rosaceae). Turkish journal of botany, 37, 1145-1154. DOI: 10.3906 / bot-1205-42.

Venkatachalam, P., Geetha, N., Sangeetha, P., \& Thulaseedharan, A. (2013). Natural rubber producing plants: An overview. African Journal of Biotechnology, 12(12), 1297-1310. https://doi.org/10.5897/AJBX12.016.

Wang, S., Liu, J., Wu, Y., You, Y., He, J., Zhang, J., Zhang, L. \& Dong, Y. (2016). Micromorphological characterization and label-free quantitation of small rubber particle protein in natural rubber latex. Analytical Biochemistry, 499, 34-42. https://doi.org/10.1016/j.ab.2016.01.015.

Wickramasuriya, A. M., \& Dunwell, J. M. (2015). Global scale transcriptome analysis of Arabidopsis embryogenesis in vitro. BMC Genomics, 16, 301. https://doi.org/10.1186/s12864-015-1504-6.

Zwart, H., Krabbenborg, L., \& Zwier, J. J. (2015). Is dandelion rubber more natural? naturalness, biotechnology and the transition towards a bio-Based society. Journal of Agricultural and Environmental Ethics, 28, 313-334. https://doi.org/10.1007/s10806-015-9536-0. 